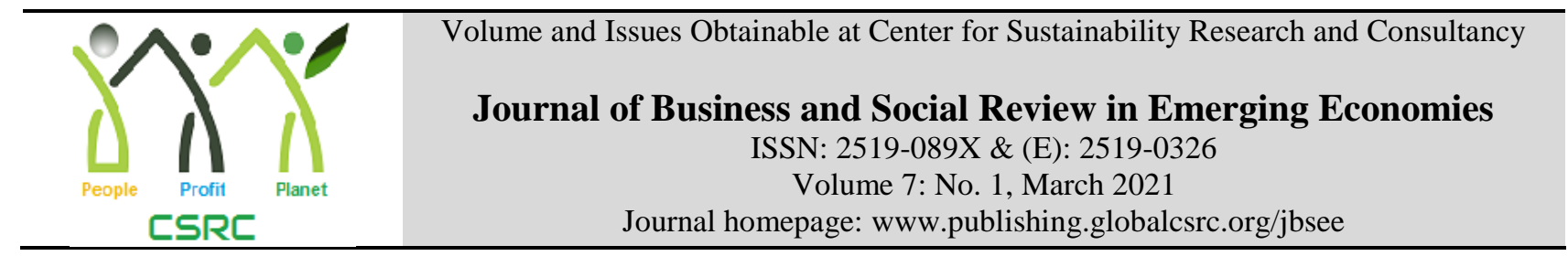

\title{
Hazard Awareness \& Practices of Biomedical Waste Management among Healthcare Staff in Apex Hospitals: A Case Study in District Faisalabad
}

Zaid Mehmood PhD Scholar in Sociology, Department of Sociology, GC University Faisalabad, Pakistan

Nazia Malik Assistant Professor, Department of Sociology, GC University Faisalabad, Pakistan

*Muhammad Shabbir Professor, Department of Sociology, GC University Faisalabad, Pakistan

Sadaf Mahmood Assistant Professor, Department of Sociology, GC University Faisalabad, Pakistan

*Corresponding author's email address: drmshabbir@gcuf.edu.pk

\section{ARTICLE DETAILS ABSTRACT}

History

Revised format: Feb 2021

Available Online: Mar 2021

Keywords

Biomedical waste

management, government

hospitals, hospital staff, health

hazards

JEL Classification:

MO, M1
Purpose: The waste produced in the course of healthcare activities carries a higher potential for infection and injury than any other type of waste. Design/Methodology/Approach: Using a qualitative approach, the study was conducted in two Apex hospitals i.e. Allied Hospital and District Head Quarter hospital Faisalabad, Punjab, Pakistan from 05 August to 15 October 2019. Consuming a semistructured interview guide two focus group discussions (FGD) were conducted in each hospital and the participants were conveniently recruited. Each group was consisting of eight members who were directly involved in the creation and handling of biomedical waste (BMW). The thematic analysis method was used to analyze the data. Findings: The sanitary staff had insufficient knowledge about BMWM and about the BMWM/HCWM rule (2005) Pakistan. Also, there was no proper mechanism of training of the staff regarding waste management mean. While BMW was being disposed of according to BMWM rule (2005) Pakistan. Implications/Originality/Value: There is a weak mechanism of implementing proper BMWM in the hospitals where no training, no accountability, and no punishment was being executed against the violation of BMWM Rule 2005 Pakistan. So, a strict policy is required for its implementation.

(C) 2021 The authors, under a Creative Commons AttributionNonCommercial 4.0

Recommended citation: Mehmood, Z., Malik, N., Shabbir, N. \& Mehmood, S. (2021). Hazard Awareness \& Practices of Biomedical Waste Management among healthcare Staff in Apex Hospitals: A Case Study in District Faisalabad. Journal of Business and Social Review in Emerging Economies, 7(1), 57-62

\section{Introduction}

Biomedical waste (BMW) produced by the hospitals is hazardous and infectious if not handled, transported, and disposed of in an appropriate manner ${ }^{1}$. BMW could be either in liquid or solid form and is produced during the medical investigations, treatment or the process of immunization on humans and 
animals ${ }^{2}$. This waste is much different from the municipal waste as it includes human body parts, used syringes, sharp needles, laboratory samples, human body wastes and fluids, microbiological cultures and laboratory waste ${ }^{3,1}$. Many infectious diseases like hepatitis, HIV infection, tuberculosis and enteric fever can be spread as a result of inappropriate disposal of this waste ${ }^{1}$. Mishandling of biomedical waste is creating serious risk to environment and health of the patients and healthcare workers ${ }^{4}$. It is important that the segregation of waste be made possible at the source. The reuse and recycling of waste should also be given serious consideration ${ }^{5}$. The hospitals have becoming a hub to spread diseases due to poor awareness among the paramedical staff, nurses, doctors and administrators ${ }^{6}$.Most of the professional had no access to the proper training for the management of infectious waste in hospitals ${ }^{7}$. Lack of regulations and law regarding biomedical/ infectious waste management has encouraged the reuse and recycling of unhygienic waste. Although, Pakistan is trying to implement waste management techniques and creating awareness, yet the attitude of public and staff has not been changed ${ }^{8}$. The doctors and the nurses have better awareness for waste management in comparison to the other staff working at hospitals ${ }^{9}$. There are set rules for the management of biomedical waste across the world. But no strong legislative measures for the implementation of BMWM practices even among the qualified hospital staff. As a result, the improper practices of BMWM are creating risk for the general public and environment ${ }^{10}$.It is a fact that earlier studies have been conducted predominantly on knowledge, attitude, and practice of BMW among doctors, and nurses. But no study focused the lab technicians, and sanitary workers who are directly involved in the process of BMWM. So, the current study was conducted among these segments to examine the level of knowledge, and awareness of BMW management procedures. The objective of study was to identify the knowledge/ awareness of BMW management procedures among healthcare staff and to investigate the extent of practical application of the biomedical waste management handling process Act (2005) in hospital.

\section{Review of Relevant Literature}

Mandal, S. K., and Dutta, J. (2009) biomedical waste is given a special aspect, since it is infectious and harmful. It may increase illness or be hazardous to individuals. If not isolatedor handled in a specified way; biomedical waste has the potential to pollute the hospital waste. M unicipal waste was disposed of after being transported and collected as the result of waste produced in hospitals and healthcare facilities are different from general waste. Although biomedical waste can require many systems, as it contains animal and human tissues, body parts, fabrics, plaster of Paris casts, gauze, industrial waste, liquid-pharmaceutical left-over, laboratory and blood waste. Biomedical waste created at various facilities of health care poses risks to environment and to the health of public.Inadequate disposal and treatment can also spread the infectious diseases such as AIDS, HIV, enteric fever, hepatitis, and tuberculosis.

Thapa, M. Et al (2015) identified the release of carcinogens which caused breast cancer are due to solid waste surgical gloves, catheters, urine and blood bags, bottles, syringes etc. through burning plastics as some examples of plastic use in health care. Plastic is also a major concern for the environment and safety, primarily because of its non-biodegradable existence. Both disposable plastics must be torn before removal of the vendor. It's also really important to reduce plastic waste generation.

Pakistani studies show that for every hospital bed occupied, about $1.35 \mathrm{~kg}$ of surplus is generated daily. In 2006, there were almost 92,000 beds in Pakistan's hospitals and almost two kilograms of waste created by per bed daily. Almost 0.8 million tons of waste is generated daily. Studies in Pakistan say that many doctors and hospitals who operate individualistically do not obey the HCWM procedures that expose themselves, other patients and staff to infection and sharp injuries. In Pakistan the waste of hospital spreads illnesses, and it also converts into the target of hunters collecting used syringes that are re-sold after recycling on the market for the reasons of personal finance. In particular, the Janitorial workers of Pakistan were exposed to be involved in sale of the syringes used to the open market at a US\$ 0.06 to 0.2 every syringe's selling price. A report reported that more than once in their lives about 52 percent of doctors have suffered needle prick injuries. In lower rates the health workers of Pakistan's health care centers suffered far more from serious damages as compared to those who were in hospitals and almost 54 percent of health workers took the 
damages.

In 2015, WHO identified the lack of management, knowledge of comprehensive laws and regulations regulating the health care waste management. This promoted reuse of surplus material and the unhygienic recycling. Pakistan was in a process of awareness rising and introducing strategies for the control of hospital waste. If the attitudes of the workers and the public towards this were not modified, the concerted efforts required could fall short. It was easy and appropriate for hospital personnel to participate and attend regularly the trainings of HCWM practice. Staff could become more helpful in undertaking these training if the latter were combined with certain competitive benefits that encouraged lively participation from cadres of all staff and were highly financially possible.

Ismail et al (2013) explained in his research that information of bio-medical waste and color-coding handling risks was very low, particularly among Class IV waste handlers, so training and retraining on bio-medical waste management workshops were required. Since there had been a history of multiple needle stick injuries among class IV waste handlers, it was important to provide them with personal protective gear like masks, shoes and gloves and to encourage them to use it and report Tetanus and Hepatitis B to their seniors immediately in case of injury etc.

Asante et al. (2013) explained in his research color labeling of waste containers and plastic bags (Brown for hazardous waste, Yellow for infectious waste and Black for general waste) was used to promote the efficient classification of health-care waste but, sadly, 'no one of these 120 health-care centers visited (including teaching hospitals, general hospitals, specialist hospitals, herbal hospitals and clinics) did not use such colors for the purposes of treatment.

Mahwish. et al. (2013) explored in both public and private hospitals some cities (Khyber Pakhtunkhwa, Lahore, Karachi, and Islamabad) of Pakistan show that the left-over produce was kept mixed in a small basket located beneath every bed, the color coding wasn't present, no proper transportation and collection were observed and only exceptions were placentas and blood products separately stored and subsequently removed by a governmental disposal agency. The most prevalent method of waste management was observed as incineration and open burning and the waste was eventually disposed of at the open site of disposal along with general waste. The study outcome also showed that situations in private hospitals were rather better than those in government hospitals.

Ali et al., (2015) consequently, keeping in mind the ultimate aim of solving this problem, it was important that medicinal waste be properly disposed of, which must be done from the basic level. The environmental issues related to the maltreatment of biomedical waste were also communicated to the local electronic media over and over again.

\section{Research Methodology}

This study was based on the hospital laboratory staff and the sanitary workers who are directly engaged in the process of handling BMW in the apex hospitals i.e. Allied Hospital and District Head Quarter Hospital of district Faisalabad Punjab, Pakistan during 05 August to 15 October 2019. Using Qualitative research methodology two focus group discussions were conducted in each hospital and every focus group was consisting of eight members. Convenient sampling method was used for selection of the research participants.

The participants were four lab technicians and four sanitary workers from each hospital. An interview guide consist of with many probing options was used for FGDs. All the data was written on paper and interpret in the same wording. A native facilitator used local language (Punjabi) to conduct the FGDs, so a comfortable environment was provided to the participants. Handwritten notes and audio records were taken by two research assistants during the discussion. Five steps thematic were used to analyze the data analysis and its procedure was followed as described by Braun and Clarke. The informed consent was taken from respondents prior to conducting interviews. The advance research board of the Government 
Collage University Faisalabad approved the study protocol.

\section{Thematic Analyses}

\section{Theme 1. SOPs and Knowledge about BMWM}

The SOPs of handling BMWM were discussed during the FGDs. In was found that BMW was disposeoff using containers of various colors (yellow, red, black, and blue.) by the hospital staff. Color coding helps to distinguish different types of waste in different containers/ drums. For example, red containers were used for Blood stained waste like blood bags, IV sets, infected swabs, and tissues, organs etc. yellow containers were used for objects with sharp edges like blades, needles, and black for the general purposes. Laboratory Staff had general awareness about the use of containers having different colors for different types of waste. A participant (Lab technician), for example said that;

"The black container is for noninfectious waste, yellow for the objects that can also cause infections and also have sharp edges, and the red for solid infectious waste"

On the other hand, it was observed that the many sanitary workers participants were less familiar with the rules of proper BMW. Many sanitary workers were illiterate, and the remaining was less educated. Also, they shared that special trainings for this purpose were not given to them. For example, one of the respondents shared:

"I am working as sanitary worker in the hospital for two years. No special training has been arranged during this period."

\section{Theme.2 Practices of BMWM}

It was found that the waste was not properly segregated at source. The sanitary workers were often observing this practice and they sometimes segregate it by themselves and many times not. One of the sanitary workers reported it as

"I often observe that the noninfectious waste bin contains infectious waste. I usually shift it in the infectious container. But it is not possible every time as we have no time to segregate each and everything."

Such kinds of behaviors indicate that the waste was not being segregated at source properly by hospital staff, and the sanitary staff was also reluctant to separate out it due to the lack of time. It is also a difficult and time-consuming job to separate each and everything from each waste container.

The BMW must be burn in the incinerator and both the hospitals were following the practice. But incinerator of one Hospital was out of order as one of the participants shared that:

"This waste was burnt through insinuators. However, from last two months there is technical fault in the waste insinuators. A truck collects the infectious waste and I don't know where it has been gone."

In such situation it would be difficult to adopt and follow proper practices of BMWM by the illiterate staff.

\section{Theme 3. Non strict policies}

It was also shared by participants that they often observe non-implementation of legislations about the proper disposal of hospital waste. A lab technician said that

"The workers often sale out the plastic waste such as used syringes, drips, and IV sets to the scrap dealers. I do not hear even once that a single person has been terminated from the services of face prosecution on such sort of violations". 
In the situation like this, by selling the hospital waste to the scrap dealers, the illiterate sanitary workers could create serious environmental issues.

According to the sanitary workers it was impossible to $100 \%$ segregation of waste at source because not only the patients but also the doctors, and Para medical staff were not following the practices of the same. On sanitary worker for example said that

"Various times I see that the staff nurses, lab technicians and even doctors dispose of syringes without cutting their needles in the wrong containers. But nobody restricts them to do so."

In such scenario, it would be too much difficult to motivate the doctors, paramedical staff, and the sanitary workers for following the proper BMWM practices. The improper practices of BMW management are creating risk for the general public and environment.

\section{Discussion}

Most of the participants had insufficient knowledge about the rules of BMW handling 2005. Containers of various colors were used by the hospital for different types of waste according to the SOPs. But the patients, paramedical staff, and even doctors were not using the proper container to discard the waste. Also, the sanitary workers did not receive proper trainings of BMWM. In the absence of proper training structure, it is almost impossible to expect proper disposal of BMW. The value of training on BMWM should be overemphasized. Lack of such kind of training leads to unawareness at all levels of the hospital staff. Effective waste management and clean environment are not only a legal obligation but also a social responsibility.

The waste was not being segregated at source which was a major problem of dealing with BMW because once waste of various types is mixed, it has become too much difficult to segregate at the next step. The mishandling of BMW is serious risks to environment, health of the patients and healthcare workers. Safe and effective BMW management practices and proposed proper policies and institutional plans along with proper training and feedback from the healthcare workers is suggested.The incinerator of a hospital was also out of order for two months. In the absence of incinerator, it is obviously hard to dispose of BMW in time.

Non-implementation of legislations about the proper disposal of hospital waste was also observed. Patients, Para-medical staff, and doctors all were violating the rules of segregating the waste. Many sanitary workers were even selling the BMW to the scrap dealers to earn surplus money, and no one was face prosecution, or any punishment from the higher authorities on such kind of serious harm to the society. WHO report (2015) also pointed out that lack of regulations and law regarding biomedical/ infectious waste management has encouraged the recycling of unhygienic waste. Although, Pakistan is trying to implement waste management techniques and creating awareness, yet the attitude of public and staff has not been changed.

The above experiences were also explored in a research that there was a low level of knowledge and understanding among health care staff about hazards in the generation of BMW, type, rules, and legislation effect the process of BMW disposal. Knowledge, among lab technicians and sanitary workers about biomedical waste management's handling is very important for proper disposing of BMW in the way of policy, rules, legislation, and color-coded bins ${ }^{13}$.

\section{Conclusion}

The analysis of the study reveals that the SOPs were standardized but their implementation mechanism was too much weak. The patients and hospital staff were violating the principles of segregating the waste at source. Due to this infectious waste was being mixed with noninfectious and its segregation at the next step was almost impossible. The sanitary staff had insufficient knowledge about BMWM and 
about BMWM Rule 2005 Pakistan, and they also did not receive proper training for the BMWM. Also, some sanitary workers were involved in selling the infectious waste to the scrap dealers that is much harmful for the society.

It can therefore conclude that there is weak mechanism of implementing proper BMWM in the hospitals where no training, no accountability and no punishment was being executed against the violation of BMWM Rule 2005 Pakistan.

\section{Recommendation}

There is needed to go beyond the traditional practices of waste management and implement innovative methods for the BMWM to protect the community health and environment. A strict policy is needed that may punish the staff on violation of BMWM policies and conduct proper training of the staff in this concern.

\section{References}

Mandal, SK, Dutta J. (2009) Integrated bio-medical waste management plan for Patna city. Institute of Town Planners, India Journal, 6(2), 1-25

Biswal, S. (2013) Liquid biomedical waste management: An emerging concern for physicians. Muller Journal of Medical Sciences and Research, 4(2), 99

Pandit, N, A, Tabish, SA, Qadri, GJ, \&Ajaz, M. (2007). Biomedical waste management in a large teaching hospital. JK Practitioner; 14(1), 57-59

Mathur, V, Dwivedi, S, Hassan, MA, \&Misra, RP. (2011) Knowledge, attitude, and practices about biomedical waste management among healthcare personnel: A cross-sectional study. Indian journal of community medicine: official publication of Indian Association of Preventive \& Social Medicine, 36(2), 143.

Deress, T, Hassen, F, Adane, K, \&Tsegaye, A. (2018) Assessment of knowledge, attitude, and practice about biomedical waste management and associated factors among the healthcare professionals at DebreMarkos Town Healthcare Facilities, Northwest Ethiopia. Journal of environmental and public health.

World Health Organization (2015) Guidance on regulations for the transport of infectious substances 2015-2016.

Madhukumar, S, \& Ramesh, G. (2012) "Study about awareness and practices about health care waste management among hospital staff in a medical college hospital", Bangalore. Iranian Journal of Basic Medical Sciences, 3(1), 7-11.

Shalini, S. (2010) Awareness about bio-medical waste management among health care personnel of some important medical centers in Agra. International Journal of Environmental Science and Development, 1(3), 251-255.

Braun, V, \& Clarke, V. (2006) Using thematic analysis in psychology. Qualitative Research in Psychology, 3, 77-101. doi:10.1191/

Goyal S, Dileep CL, Mathur A, Chaudhary S, Makkar DK, Batra M, Sood P. (2015) Knowledge, attitude and practices regarding biomedical wastes among health care professionals in Sri Ganganagar city: A cross-sectional study. DHR International Journal of Medical Sciences, $6(2), 162-171$

Ismail, I. M., Kulkarni, A. G., Kamble, S. V., Borker, S. A., Rekha, R., \&Amruth, M. (2013). Knowledge, attitude and practice about bio-medical waste management among personnel of a tertiary health care institute in Dakshina Kannada, Karnataka. Al Ameen J Med Sci, 6(4), 376-80. 